\title{
THE USE OF ROBUSTNESS ANALYSIS FOR PLANNING ACTIONS IN A POOR BRAZILIAN COMMUNITY
}

\author{
Anderson Amendoeira Namen \\ Rio de Janeiro State University (UERJ) \\ Nova Friburgo - RJ \\ aanamen@uol.com.br \\ Cláudio Thomás Bornstein* \\ COPPE / Federal University of Rio de Janeiro (UFRJ) \\ Rio de Janeiro - RJ \\ ctbornst@,cos.ufrj.br \\ Jonathan Rosenhead \\ London School of Economics \\ London WC2A 2AE - UK \\ * Corresponding author / autor para quem as correspondências devem ser encaminhadas \\ Recebido em 03/2009; aceito em 03/2010 após 1 revisão \\ Received March 2009; accepted March 2010 after one revision
}

\begin{abstract}
This paper reports on the use of Robustness Analysis for planning actions in a poor Brazilian community. The focus is on food and agricultural production and the project is based on a participatory approach incorporating both community-driven development and sustainability in food production. A comparison is made with other soft Operations Research (OR) methodologies and first actions and results are reported.
\end{abstract}

Keywords: soft OR; robustness analysis; sustainable community development.

\section{Resumo}

Este artigo propõe o uso da Análise de Robustez para o planejamento de ações em uma comunidade de baixa renda no Brasil. O foco está na produção agrícola e de alimentos e o projeto fundamenta-se em uma abordagem participativa incorporando tanto o desenvolvimento voltado para a comunidade quanto a sustentabilidade na produção de alimentos. Apresenta-se uma comparação com outras metodologias de PO soft e relatam-se alguns resultados e ações.

Palavras-chave: PO soft; análise de robustez; desenvolvimento comunitário sustentável. 


\section{Introduction}

Granja do Céu (Heaven's Grange) is a small community located in Nova Friburgo, a little town situated $120 \mathrm{~km}$ from Rio de Janeiro, with 69 families and a population of approximately 230 persons living in a small hilly area. The main objective of the project reported here was to make the community or part of it able to produce its own food using organic production techniques. According to Cobb et al. (1999) organic production helps retain local employment, improves social cohesion and generalizes new economic initiatives. Non-organic production is generally carried out on a larger scale and for that reason has lower costs which local production could never achieve. Organic production, on the other hand, offers the possibility of realizing better prices with less competition. The focus on organic production is supported by the fact that the use of pesticides is not part of the cultural background of the community. Pesticides are also expensive, especially when used on a small scale.

Granja do Céu is what Ruben \& Pender (2004) call a less-favoured area (LFA). Such an area may be described in terms of scarce resources, high vulnerability, low returns to production factors, chronic and persistent poverty, limited access to markets and infrastructure, etc. According to the above mentioned authors, decentralization and community-driven policies may enhance sustainable development in LFAs.

The client here is a non-governmental Christian (Roman Catholic) organization called Pastoral da Criança (PDC). Two analysts, both among the authors of this paper, worked with the PDC helping with technical questions but also participating in the decision process. Three members of the PDC together with the two analysts did constitute the Decision Making Group (DMG). This team conducted the interviews and led the meetings with the Granja do Céu community.

The project started in 2003 and three years were necessary to develop the model and get to the first results. Work is still running and, as will be seen in the last two sections of the paper, constant changes were necessary to adapt to local circumstances. Therefore maintaining flexibility was essential for the project.

All the expenses were paid by the members of the DMG. Participants of the PDC are volunteers and are not rewarded. The same applies for the two analysts. Only the agronomist (see section four) is being paid by the NGO to which he belongs. Meetings were held in a room contiguous to the church which belongs to the community.

The first phase of the project, lasting about two years, consisted in getting information about the community. The DMG came to the conclusion that sustainability would be better achieved through food production allowing certain autonomy of the community with respect to this important issue of basic needs. Therefore interviews were centred in order to obtain more information about water resources, land, agricultural knowledge, available production features and family needs. The interviews also allowed the group to strengthen links with the members of the community.

During this phase several relevant experiences of sustainable development were studied. Some of the initiatives of the Movimento dos Sem Terra (MST - movement of the Brazilian landless rural workers) are of particular relevance to the question of sustainability. Established in 1984 the MST is the most active organization in the Brazilian countryside and maintains a high level of participation and commitment among members (Wolford, 2003).

During the first phase of the project it became evident that sustainable development would not be achieved through a short-term effort. The second phase, therefore, was the 
development of a long-term planning process to allow for an appropriate use of the main resources of land, water, labour, transport facilities etc.

Problem Structuring Methods (PSM) furnished the framework for the decision process. Formal assessment techniques were used in a participatory decision-making context. Due to a high level of uncertainty Robustness Analysis (RA) was used. According to Antunes et al. (2006) sustainable development decisions require the active engagement of stakeholders in addition to some kind of formal appraisal of alternatives.

This paper begins by describing the local community. It then discusses the decision process involved in developing a sustainable locally grown food policy, as well as a method for assessing robust choices. The first resulting actions taken by the community are then presented, followed by some conclusions.

\section{Information about the Granja do Céu community}

Working with the community since 2000, the PDC has three main activities, focusing on the health and education of children up to six years of age. The first of these activities is a monthly visit of PDC members to Granja do Céu families that include children or a pregnant woman. The purpose of this visit is to follow the general development of the children, examining issues like nutrition and education; but attention is also paid to more general aspects such as employment of family members, domestic violence, etc. The second activity is the monthly weighing day. On these occasions, as the name indicates, mothers and/or fathers meet, generally in a room near the church, children are weighed and their health is examined. In addition, general community problems such as infrastructure (lighting, water, etc.), employment and education are discussed. Thirdly, there is a monthly meeting of the members of PDC where the whole situation of the community is examined, their own work is evaluated, problems are discussed and solutions are proposed.

Although there is no restriction on the religious background of the families (as a matter of fact several evangelical Christian families participate in the program), Catholic values (for example the importance of baptism, communion, etc.) are assumed and at the weighing day there is generally a prayer or some other religious ritual.

Visits were made by the analysts together with PDC members to several families whose homes have a kitchen garden, as well as to families which own some cultivable land. These visits included both families with and without agricultural knowledge. The picture which emerged is as follows (see also Namen, 2007):

- More than $40 \%$ of the families rely for their livelihood on occasional work. The other families divide, in approximately equal numbers, between families whose members are unemployed, live on a pension, or have regular employment. This means that only $20 \%$ of the families have one or more members employed in a regular job.

- Twenty five percent of the families live below or just at the poverty line. The United Nations Development Programme's poverty line for Brazil is around US\$ 30 per person monthly. For an average 4-person family this converts into a monthly income of US\$ 120 . Forty eight percent of the families have incomes in the range US\$120 to US\$ 240 and $14 \%$ get more than US\$2 240 . There was no information on the income of the remaining families.

- Adults have a very low level of educational attainment. 
- Many people begin activities (educational or otherwise) and then give them up. There are many reasons for this, ranging from lack of motivation to personal circumstances. For example, a mother may not have somebody to leave her children with. This problem tends to be worse for activities held outside the Granja do Céu area.

- Low self-esteem is common. There are many cases of alcoholism and domestic violence (between parents and between parents and children). However, very few cases of criminality and almost no case of illegal drug trading, drug consumption or the criminal use of firearms have been reported.

- There are many family relations among members of the community. Couples are frequently formed in which both partners belong to Granja do Céu.

- The participants in PDC meetings are mainly women.

- Some families have kitchen gardens, while others keep small animals such as chickens or pigs. There is a variety of small areas in the community which can be used for planting vegetables. These areas are generally in front of or behind houses. Some vacant lots without clearly established ownership are also available. Near the church there are two areas of this kind, one rather small and the other bigger.

- Collective work has been carried out sporadically, mainly by men. For example, the church was constructed collectively, with donated raw materials. Generally the success of such activities depends on a certain festive mood, involving also a joint lunch or dinner, a celebration, etc. which boosts the motivation of the group. Historically, the Granja do Céu community has had low levels of participation and little cooperative work.

A plan of action for the project was developed based on the information outlined above. (It will be presented in the next section.) As already mentioned, the project's main goal is sustainability in food production, necessarily based on organic agriculture. Issues which had to be taken into account included respect for the cultural background of the community, and the need to improve the levels of participatory work, solidarity and awareness of civil rights.

The concern with sustainability extends to the avoidance of external dependency. Help offered to the underprivileged is all too often provided in a top-down style, i.e. in a paternalistic manner that reinforces dependency. This can easily undermine any professed aim of improving community autonomy. In the project reported here reliance on governmental support was avoided because, in Brazil, it is all too frequently associated with the pursuit of electoral advantage.

The plan of action adopted is based on family production rather than some kind of more collective process. According to Souza (2002) and Brenneisen (2004) peasants frequently have a certain resistance against the latter. Collective production is often based on common property and for the residents of Granja do Céu, individual property has an important meaning. It provides the basis for family life and land is often the main legacy for the children. Besides, collective production is generally based on rigid time schedules and control procedures, which, due to their cultural background, community members would have a certain difficulty in accepting. Difficulties also arise in measuring productivity and consequently in distributing the income which results from concerted activities. Nevertheless, some particular collective actions like the joint marketing and transportation of production, the shared purchase of agricultural inputs, and the improvement of the common water supply and infrastructure will be considered here as possible alternatives. 


\section{Robustness analysis and Problem Structuring Methods}

The problem described in section two qualifies as an Ill-Structured Problem (ISP). ISPs also called messes (Ackoff, 1981), or wicked problems (Rittel \& Webber, 1973) are those in which it is believed that the factors to be taken into account, the relationships between them and the objectives to be achieved cannot be objectively determined or at least consensually agreed. Deliberations are obstructed by bewildering complexities, by uncertainties about future conditions and about the actions of others, and by differences in priorities and interests within the group. A family of methods known as Problem Structuring Methods (PSMs) has been specifically developed to enable progress to be made under these conditions (Rosenhead \& Mingers, 2001). It is now increasingly accepted that the methods of Operational Research (OR) can be arrayed along a spectrum from hard to soft. PSMs belong to the latter with the earlier largely optimizing approaches now known as hard methods. It was a member of the PSM family, Robustness Analysis (RA), which was used to help tackle the agricultural development problem in Granja do Céu. RA is particularly suited to situations with high uncertainty and the possibility of taking decisions sequentially. It provides a methodology which preserves flexibility by just evaluating alternative early commitments.

Such flexibility supplies a valuable insurance policy for responding to the unpredictable changes which may, indeed are likely to, occur over the extended period during which many projects are developed. These changes may result from data or information having been inaccurate, from unforeseen political events or other modifications in the environment, or from unexpected reactions of the community. It is often helpful to identify representative possible future states of the environment of the system under consideration. Such states are known as scenarios: each scenario is a structured account of a possible future. Scenarios describe futures that could be rather than futures that will be (van der Heijden, 1996; Peterson et al., 2003). The organizing principle of the robustness approach is to maintain the possibility of achieving good performance of the system across a wide range of different future scenarios (Best et al., 1986). The emphasis in robustness may mean a shift from a rather rigid concept of optimality to a more nuanced approach.

The PSM family includes a range of methodologies, each with a particular emphasis. These include SODA - Strategic Options Development and Analysis (see Eden, 1988 and Eden \& Ackermann, 1998), SSM - Soft Systems Methodology (see Checkland, 1999a and 1999b), SCA - Strategic Choice Approach (see Friend \& Hickling, 1997) and Drama Theory (see Bennett \& Howard, 1996 and Howard, 1996). Rosenhead \& Mingers (2001) provide an introduction to each of these methods, and an overview.

Why was RA rather than one of the other PSMs selected for use in Granja do Céu? SODA, SSM and SCA each make extensive use of facilitated workshops in which the elements of the problem situation, which participants see as relevant, are elicited and related to each other through the framework of the method's modelling language. This requirement for a wide and open participation by stakeholders was an argument against using them in Granja do Céu. (Such participation is a possible feature of Robustness Analysis but is less central.) Several meetings were held with members of the community, but participation was qualitatively limited - i.e. people would listen passively rather than give their opinions. This appeared to be a problem of limited confidence in making contributions to discussion in relatively large assemblies. Reaction rather than action was the dominant attitude and even the former required sufficient stimulus. In rural or peri-urban areas, poor people are generally shy and are unused to participation in meetings. 
Using the inevitably over-simplified, categorisation from hard to soft OR methods, it is possible to say that RA is towards the 'harder' end of the PSM spectrum. Both more analytical and more participatory methodologies for Robustness Analysis have been developed (Rosenhead, 2001, pp.200-206). This dual possibility indicates that Robustness Analysis makes a less sharp break with the previously established conceptual frameworks of Operational Research than do some other members of the PSM family. Unmodified, Robustness Analysis does not offer a general purpose problem identification methodology. However this relative weakness of synoptic power is compensated by its higher level of decision focus. That is, it can take the problem structuring process more purposefully towards commitment.

Of course in a problem situation such as that at Granja do Céu, participation in the project, if not in the details of the analytic methodology, is essential. Without this the project is unlikely to be well targeted, or to gain the confidence of those who it is supposed to benefit. With this in mind, visits were made to a sample of homes of members of the community. In a familiar environment, surrounded by people they know, with few outsiders present, they do express their opinions. At Granja do Céu information and data was collected mostly through such home visits. Although members of the Granja do Céu community did participate in the definition of the problem they did not participate in the implementation of the RA methodology.

Another reason for using RA instead of SODA and SSM is that the two last are designed for use in situations where there is lack of clarity about the objectives which should be attained and where there are divergent views about the definition of the problem. This was not the case at Granja do Céu where the problem and objectives were well defined; however complexity and uncertainty nevertheless made it unclear what decisions should be taken. RA is a methodology mainly directed towards action and decision making.

Another PSM, drama theory, is more appropriate for situations of conflict, such as, for example, negotiations between employers and employees, adversarial manoeuvres between commercial enterprises etc. right up to the possibility of military engagements. In these circumstances, emotional (seemingly irrational) behaviour is often associated with decision making. Drama Theory illuminates the function of such behaviour. However these conditions did not apply in the case of Granja do Céu.

The level of uncertainty involved in the planning process in Less-Favoured Areas (LFA) in a developing country is one further argument for the adoption of RA. Not only is the availability of resources subject to extreme fluctuations, but in addition there can be large changes in the level of participation, infrastructure is commonly precarious and natural disasters may introduce the need for major adjustments. Risk is always present in a poor community in a third world country and may result in radical changes within the planning process. Among the established PSM methods only SCA and RA are concerned with the management of uncertainty. In this case RA, which has a less elaborate structure and tool repertoire than SCA, was thought to be the better option to use in Granja do Céu. As a matter of fact, in the DMG meetings, the three PDC leaders, which had no experience with OR techniques, found the RA technique quite easy to understand.

The first step in robustness analysis is to build a sequential decision chart (SDC) (see Figure 1). The SDC displays the set of relevant decisions which can be taken up to a certain planning horizon. Decisions are arranged horizontally in time sequence. The vertical dimension represents the possible alternative choices at each particular decision point. As mentioned before, using robustness as a criterion results in maintaining as much flexibility as possible. 
It does not prescribe a complete 'solution', but relies on taking only those decisions which have to be taken now, leaving all further actions for future choice. More details about the methodology can be found in Rosenhead (2001), Wong \& Rosenhead (2000), Bornstein \& Namen (2005), Namen (2007) and Namen et al. (2009). The emphasis of the last reference is the RA methodology itself, whereas the present paper makes a better comparison with other soft OR methods and a more detailed description of the first actions and results (see section four).

In Figure 1 decisions are arranged in seven sets or stages. The first stage concerns in defining the level of participation of the project. The lowest level would mean involving only those people who already have kitchen gardens. Other possibility is including families that own agricultural land, do not cultivate it but have interest in participating in the project. The highest level of participation would mean involving in addition other interested people even if they do not own cultivable land.

In order to test individuals' levels of engagement with the project, a filtering process was thought to be necessary. Options for this process include participation in a course, or involvement in the construction of a cistern or water tank. The level of commitment to these activities supplies a criterion for the selection of families that will be engaged in the project.

The next two decision stages define the extent to which the two main production inputs, water and land, should be used. With respect to water, the lowest decision level consists in using only the available resources, reaching, at the highest level, the construction of a cistern which may collect rainwater, or a larger water tank which may store water from an additional source. With respect to land, the lowest level of usage of this resource just considers the cultivable land of the families involved. Other possibilities include two areas near the church. The smaller area may be cultivated by one family but the bigger area would require the labour of several families. This last alternative poses an additional difficulty due to conflicts that may arise from the shared use of the land. Finally it is also possible to lease additional land.

The fifth stage considers the scale of production and some associated features. Organic certification by an accreditation organization, special packing as well as the processing of the vegetables in the form of salads, are all possible options.

The final two decision stages concern the distribution of production and transport facilities. Possibly there will be a production surplus, i.e., production exceeds the need of the producer's family. This surplus can be used as animal food, exchanged for other goods or food, given for free or used to make soups for lower income families. For these cases no transportation facilities are needed. Alternatively, the production can be sold to middle class families living in the neighborhood, street markets or a supermarket. Another possibility consists in using PDC contacts to find possible buyers of the agricultural production of the community (we call this option PDC's friends).

Moving downwards in Figure 1 corresponds to an increase in the scale of the activities. Links between decisions are represented by arrows and follow a logical sequential order. For example, if only people with kitchen gardens are involved, enrollment in a course may be sufficient to select participants. Since only their land will be used there will be no need for additional water resources. The consequence will be a small scale production, with or without certification. Only the lower levels of transport facilities need to be considered, i.e. no van or truck will be required. In this case either the production surplus will not be commercialized at all, or it will be marketed in the neighborhood and/or sold to PDC's friends. 


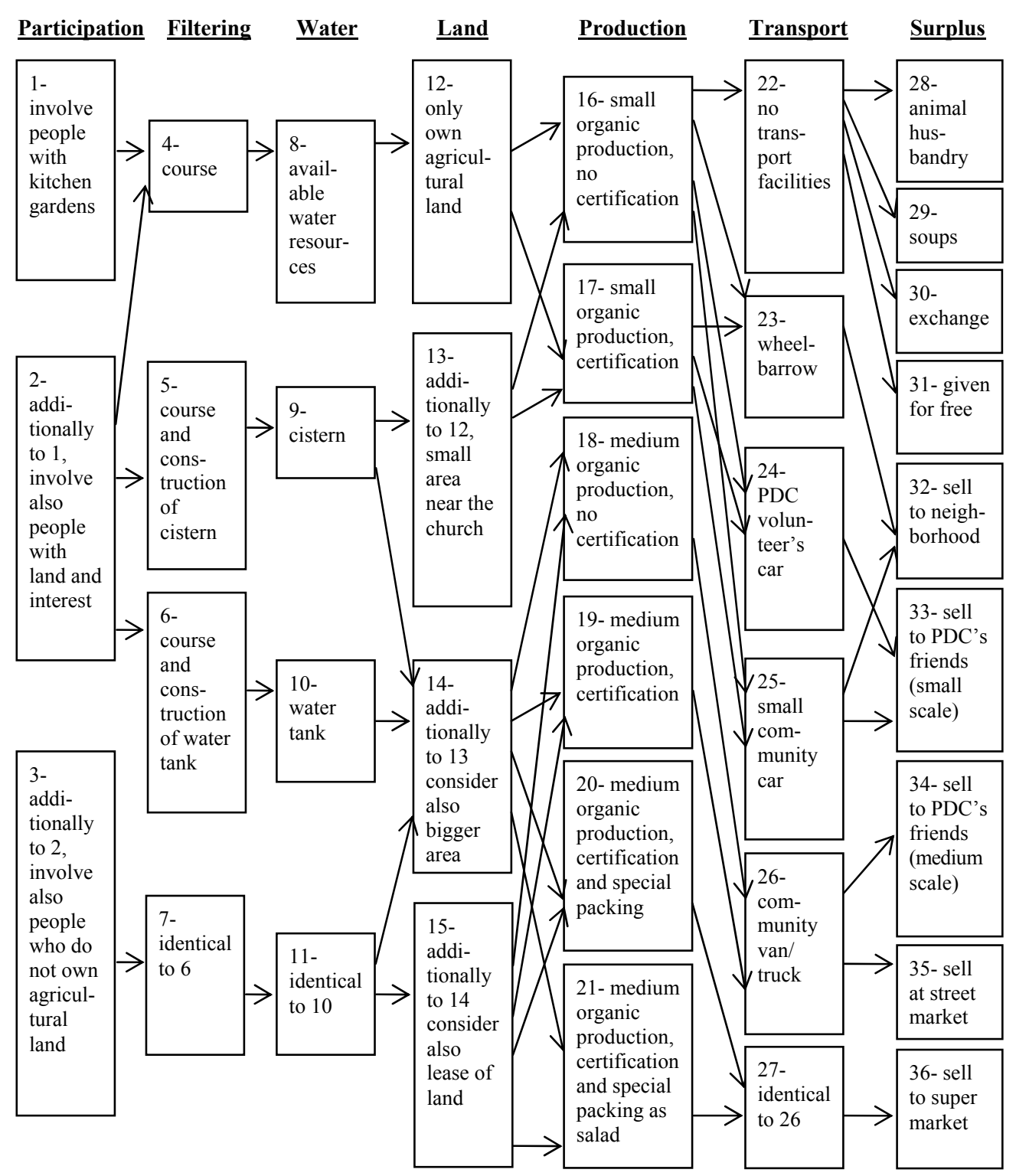

Figure 1 - Sequential decision chart.

Some nodes or decisions in Figure 1 have been duplicated in order to distinguish different sequences of decisions. (This is the case for nodes 6/7, 10/11 and 26/27.) Each sequence of decisions across the seven stages results in a particular configuration of the system. In order to determine the robustness of any initial action, it is first necessary to evaluate the performance of each configuration in each of the plausible future contexts (called scenarios) identified by the DMG. For each scenario a configuration's performance may be classified as very desirable, desirable, undesirable, very undesirable or questionable. 
Three future scenarios, $F 1, F 2$ and $F 3$ were considered. $F 1$ assumes good market conditions, high community synergy and some available economic resources. $F 2$ also sets out from good market conditions but presumes low community synergy and few available economic resources. Finally, $F 3$ considers bad market conditions, low community synergy and no economic resources. Of course a greater number of scenarios could have been created considering a more detailed description of possible future events. However, this would increase difficulties at the evaluation stage. After several meetings of the DMG a compromise between realism and tractability led to the three scenarios described above.

As already mentioned, robustness analysis makes commitments only with respect to the first stage of decisions. All subsequent decision stages remain open until commitments are required. Initial commitments should, if possible, be made so that under each possible scenario there is a range of configurations they can lead to, which perform well. Just as an illustration, suppose that decision $D 1$ (involve only people with kitchen gardens) is an element of each member of a set $A$ of configurations; and that $D 3$ (involve people with kitchen gardens and people with interest even it they do not own agricultural land) is an element of each member of a set $B$ of configurations. For the sake of simplicity, let us say that sets $A$ and $B$ are disjoint. If, when considered across the whole range of scenarios, the configurations in set $A$ clearly outperform those in $B$, then, according to robustness analysis, $D 1$ is preferable to $D 3$.

In practice the question of outperformance across the scenarios may not be obvious, and quantitative measures can help to capture the relative degrees of flexibility which are maintained. This is done by the robustness and debility scores. In a particular scenario the robustness score of any initial commitment $i$ is the ratio of the number of desirable and very desirable configurations reachable from decision $i$ to the total number of desirable and very desirable configurations of this scenario. The debility score is defined similarly, but in terms of unsatisfactory configurations - so low debility is preferred. Different weights may be used to discriminate desirable from very desirable configurations (for more details see Namen et al., 2009).

In the present case D2 (involve people with kitchen gardens and other people with agricultural land and interest) was the decision which achieved the highest robustness score for both $F 1$ and $F 2$. Under $F 3, D 1$ and $D 2$ performed equally well. Comparing $D 1$ and $D 2$ with the help of the debility score the conclusion is that $D 1$ outperforms $D 2$ for all the three scenarios. After examining and discussing the results, the DMG came to the conclusion that the best initial choice would be $D 2$. Although $D 2$ represents higher risks it also has more chances of success. The DMG reasoned that the higher risks could be counterbalanced by future actions. The fact that RA keeps the options open reinforces this possibility.

In practice discussions, or changes of the available information, lead to repeated alterations in the formulation of the problem and hence in the SDC. Manual changes of the SDC may represent an additional burden. For these reasons Robus was developed, which, at our knowledge, is the only software available for Robustness Analysis. Besides facilitating changes in the SDC, it allows the storage of a different number of scenarios, configurations and performs the calculation of robustness and debility scores. It is free software and can be accessed at www.cos.ufrj.br/robus.

Members of the Granja do Céu community did participate indirectly in the development of the SDC, but they did not participate directly in the robustness analysis process itself. Even though robustness is itself quite a transparent and accessible concept, the full process of 
analysis is arguably too complex for the community members. In any case it should be noted that, although robustness analysis delivers important structured information for the decision process, it does not necessarily end that process. Results were presented and discussed with the community, which could have changed the decisions. In the present case no such changes were necessary.

\section{First actions and results}

As mentioned in the previous section robustness analysis led to the initial decision of involving people with kitchen gardens, plus people with agricultural land and an interest in joining (decision D2). The next decision stage is the filtering process, for which the possible options are the organization of a course and perhaps also the construction of a cistern or a water tank (see Figure 1). The course, therefore, is required whichever decision is made for the second stage. Hence, without violating the robustness approach of only making decisions when they really need to be made, the next decision was to organize the course.

In order to proceed in this way a partnership was established with ABIO (the association of organic farmers of the state of Rio de Janeiro) at the beginning of 2007. This institution has an interest in the diffusion of organic farming and links with social projects improve the image of the organization. An ABIO agronomist visited the community together with members of the DMG, and the course was organized. During the first meetings the successful implementation of organic agriculture in communities of small farmers in the Rio de Janeiro state was described, and videos were shown (see AS-PTA, 2003a and 2003b). The next series of meetings consisted in visits to the kitchen gardens and backyards of the participants. The agronomist presented cultivation techniques and organic methods of maintaining soil productivity and insect control. The idea was to complement the previous presentations with practical work.

The agronomist should be seen as a facilitator rather than as an expert. Members of the Granja do Céu community know local conditions well, and most of them have some experience in agricultural production. The objective of the meetings is more exchanging information and skills. Putting the focus on the exchange of local knowledge strengthens self-esteem, which may be more important than maximizing productivity. Increasing solidarity, the sense of collectivity and esprit de corps, knowledge and education, seems to be at least as important as producing food. After all, the latter may depend on the former.

At the reunions there should be always some practical work and participants should be asked to play an active role. For example, in one of the first meetings, participants were asked to sketch their land and house and there was a discussion about the best area to plant.

Social projects often unfold in unexpected ways. This stresses the importance of flexibility (and hence the relevance of robustness analysis). At the beginning of 2007 landslides caused by heavy rains damaged seven houses. Homeless families found shelter at neighbours, parents, etc. This fact shows the importance of solidarity among destitute people. Due to the bad environmental conditions, natural disasters are a frequent part of their life and may change the flow of events quite dramatically. In the present project the big area near the church (see 14 in Figure 1) may be used to build houses for the homeless instead of being used for agricultural purposes.

Possibly as a consequence of the present project, the Granja do Céu residents association was reactivated during 2005. The association had ceased to function during the nineties, but 
currently the meetings are well-attended. Parties and raffles are being organized to raise funds. Another possible consequence of the project was the construction during 2007/8 of a hall with kitchen and toilet next to the church. Work was done by the members of the Granja do Céu community on a labour-sharing basis. This hall and kitchen are presently being used in a cooking course which also deals with nutritional aspects. Most of the recipes which are presented at the course make use of locally grown vegetables.

There were also events that outrun the strict limits of the present project but which possibly are a result of the improvement of the self-esteem of the community. For example, during the meetings several members of the community showed interest in a computer course. The result was a free course held in the rooms of a university where one of the analysts used to work. It can be argued that this kind of knowledge is not important for people who lack more basic needs. There is no space here to pursue this subject, but even if data processing is not part of the daily activities of the members of the Granja do Céu community, knowing something about it may help to increase their self-confidence. More concretely, it may strengthen their position when dealing with authorities who frequently use the computer as a justification or excuse for failures in the consideration of the necessities of the community.

In the meetings the question of education was also raised. There is no state-supported public school near the community. Approximately $70 \%$ of the adults are illiterate. At present, the residents association is putting pressure on authorities to build a school plus kindergarten. A nursery school is important for poor communities, allowing the women to work.

The project has also had a multiplicative effect in the sense that other social actors were encouraged by the DMG to become involved (on a voluntary basis). A group of doctors visited the community discussing problems such as diabetes, anaemia and insect-borne diseases. Prevention techniques have been explained and medical tests have been carried out. Dentists gave talks about oral hygiene. In the area of sewage control, an engineer gave a talk on recycling methods and this process is being introduced in the community. All these measures aim to improve the living conditions of the population.

\section{Conclusions}

Respecting local conditions and the cultural background of the community is essential for the success of a social project. Starting from a review of initiatives in similar areas and a comparable environment, a project was developed that focuses on agricultural production. The organizing principle of the project is sustainability in the broad sense, which can only happen if the community is able to progress the work with as little interference from outside as possible. From the agricultural point of view this means no pesticides, and using organic rather than chemical fertilizers. It also means working with a diversity of independent organizations, rather than with governmental institutions. Sustainability is developed by relying as little as possible on external funds and interfering as little as possible with local patterns and habits, even if the result is some loss of efficiency. Sustainability from our perspective implies increasing solidarity and strengthening ties between the members of the community.

The project started from a familiar (individually-based) production mode. Rather than attempting to impose production on a collective basis the idea here is to keep with the community's existing cultural background. This improves the chance of a successful trajectory for the project, which it is hoped will lead to a greater future emphasis on communal actions. 
In the present project the strong ties of the PDC members with the Granja do Céu community played a decisive role in the development of the work. These connections between the PDC/analysts and the community established a relationship of confidence which removed barriers and allowed information to flow. Obviously good information is essential for the success of a project, and information flow is encouraged by mutual confidence. In Brazil (Roure \& Pádua, 2001) work in a community always depends on interpersonal relations; and ties between people play a decisive role in cooperative work (Holanda, 1995). This also applies to other countries (see Bunch, 1995; Midgley \& Ochoa-Arias, 2004 and Santos, 2006).

Following Gregory (2000) the primary goal of a structured decision approach should be to improve thinking and to sharpen communication about critical concerns and tradeoffs. A clear understanding about participants' preferences and their key values tradeoffs should be achieved. Analytical techniques may be used to improve the quality of stakeholder participation, creating a basis for informed judgments. According to Gregory (2000) the main goal in participatory decision making is decision insight rather than consensus.

Robustness analysis provides a basis for rational analysis and rational decision making when a high degree of uncertainty, indeterminacy and, why not, inexperience and ignorance, encompasses the main decisions associated with it. In the process of constructing the SDC, the main decisions and their links are discussed and a better insight of the project can be achieved. Later, by considering different scenarios it is possible to sharpen the perception of the future, of the risks involved and of the feasible alternatives of the project. Short, one of the great advantages of RA is not only the fact that it offers a tool for making decisions but also the fact that it allows the structuring of the problem in a more precise way. Contours which usually are rather diffuse in an ISP, gain a more clear and precise shape through the use of PSMs.

The Robus software makes it easier to introduce changes in the data and parameters of RA, therefore helping with the implementation of the technique. At present, Robus is being used only by the PDC/analysts. However, the intention is also to involve members of the Granja do Céu community.

According to Peterson et al. (2003) uncertainty can be confusing and demoralizing, leading to paralysis by analysis rather than decisiveness and action. However, uncertainty also has its positive sides. It can lead to humility if all participants acknowledge their ignorance about the future; it can encourage tolerance; and in a broad sense it can also inspire action because it implies that the future is not already determined but is being created by the plans and actions of people.

Recent visits have shown that some Granja do Céu residents who did not previously have kitchen gardens are beginning to plant. The PDC/analysts hope that the project may initiate a virtuous circle in the sense that an as yet small participation may bring benefits to the group. This, in turn may foster a higher level of participation, further increased benefits and so on. This virtuous circle should bring back to the community aptitudes, self-esteem and selfconfidence that should ultimately allow the community to stand on its own feet.

\section{Acknowledgments}

The authors would like to thank the two anonymous referees for the suggestions that improved considerably the quality of the paper. 


\section{References}

(1) Ackoff, R.L. (1981). The art and science of mess management. Interfaces, 11, 20-26.

(2) Antunes, P.; Santos, R. \& Videira, N. (2006). Participatory decision making for sustainable development - the use of mediated modelling techniques. Land Use Policy, 23, 44-52.

(3) AS-PTA. (2003a). Projeto agricultura urbana no município do Rio de Janeiro - curso "Capacitação de moradores de comunidades urbanas periféricas em atividades agropecuárias" (Urban agriculture project in the city of Rio de Janeiro - course "Training in agricultural activities for residents of peripheral communities"). Assessoria de Serviços a Projetos em Agricultura Alternativa, Rio de Janeiro, Brazil.

(4) AS-PTA. (2003b). Agricultura na cidade: experiência em quintais da periferia do Rio de Janeiro (Agriculture in the city: kitchen gardens in poor communities in Rio de Janeiro). Realização: AS-PTA e Triângulo Produções, Rio de Janeiro, Brazil. DVD (19 min.).

(5) Bennett, P.G. \& Howard, N. (1996). Rationality, Emotion and Preference Change: Drama-theoretic models of choice. Eur. J. of Ops. Res., 92, 603-614.

(6) Best, G.; Parston, G. \& Rosenhead, J. (1986). Robustness in practice - the regional planning of health services. Journal of the Operational Research Society, 37, 463-478.

(7) Bornstein, C.T. \& Namen, A.A. (2005). The use of robustness analysis for sustainable development in a community near Rio de Janeiro. In: Proceedings of the Fifth International Conference on Operational Research for Development (ICORD-V). Jamshedpur, India, 149-154.

(8) Brenneisen, E. (2004). O MST e os assentamentos rurais no oeste do Paraná: encontros e desencontros na luta pela terra (The landless rural movement and the settlements in the west of Paraná: agreements and disagreements on the struggle for land). Available in English at $<$ http://socialsciences.scielo.org>, accessed June 29, 2008. Estudos Sociedade e Agricultura, 12, 128-163.

(9) Bunch, R. (1995). Two Ears of Corn: A Guide to People-Centered Agricultural Improvement. 3rd edition, World Neighbors, Oklahoma City.

(10) Checkland, P. (1999a). Systems Thinking, Systems Practice. John Wiley \& Sons, Ltd, Chichester.

(11) Checkland, P. (1999b). Soft systems methodology: A 30-year Retrospective. John Wiley \& Sons, Ltd, Chichester.

(12) Cobb, D.; Feber, R.; Hopkins, A.; Stockdale, L.; O’Riordan, T.; Clements, B.; Firbank, L.; Goulding, K.; Jarvis, S. \& Macdonald, D. (1999). Integrating the environmental and economic consequences of converting to organic agriculture: evidence from a case study. Land Use Policy, 16, 207-221.

(13) Eden, C. (1988). Cognitive Mapping: a review. European Journal of Operational Research, 36, 1-13.

(14) Eden, C. \& Ackermann, F. (1998). Making Strategy: the journey of strategic management. Sage, London.

(15) Friend, J.K. \& Hickling, A. (1997). Planning under Pressure: the Strategic Choice Approach. 2nd edition, Butterworth-Heineman, Oxford. 
(16) Gregory, R. (2000). Using stakeholder values to make smarter environmental decisions. Environment, 42, 34-44.

(17) Holanda, S.B. (1995). Raízes do Brasil (Roots of Brazil). 26th edition, Companhia das Letras, São Paulo, Brazil.

(18) Howard, N. (1996). Negotiation as Drama: How “Games” Become Dramatic. International Negotiation, 1, 125-152.

(19) Midgley, G. \& Ochoa-Arias, A. (Eds.) (2004). Community Operational Research: OR and Systems Thinking for Community Development. Kluwer Academic/Plenum, New York.

(20) Namen, A.A. (2007). Utilização da tecnologia de informação como suporte no setor de alimentação e desenvolvimento auto-sustentável (The use of information technology for nutrition and sustainable development). $\mathrm{PhD}$ Thesis, COPPE/UFRJ, Systems Engineering, Federal University of Rio de Janeiro, Brazil.

(21) Namen, A.A.; Bornstein, C.T. \& Rosenhead, J. (2009). Robustness Analysis for sustainable community development. Journal of the Operational Research Society, 60, 587-597.

(22) Peterson, G.D.; Cumming, G.S. \& Carpenter, S.R. (2003). Scenario Planning: a tool for conservation in an uncertain world. Conservation Biology, 17, 358-366.

(23) Rittel, H.W.J. \& Webber, M.M. (1973). Dilemmas in a general theory of planning. Policy Sciences, 4, 155-169.

(24) Rosenhead, J. (2001). Robustness Analysis: keeping your options open. In: Rational analysis for a problematic world revisited [edited by J. Rosenhead and J. Mingers]. Wiley, Chichester, 181-207.

(25) Rosenhead, J. \& Mingers, J. (Eds.) (2001). Rational analysis for a problematic world revisited. Second edition, Wiley, Chichester.

(26) Roure, M. \& Pádua, S.M. (Eds.) (2001). Empreendedores sociais em ação (Social entrepreneurs in action). Cultura Editores Associados, São Paulo, Brazil.

(27) Ruben, P. \& Pender J. (2004). Rural diversity and heterogeneity in less-favoured areas: the quest for policy targeting. Food Policy, 29, 303-320.

(28) Santos, B.S. (Ed.) (2006). Another production is possible. Beyond the capitalist canon. Verso, London.

(29) Souza, M.A. (2002). The rural landless workers movement in Brazil: cultural, economical, educational and political dilemmas. In: XVth ISA World Congress of Sociology, v.1, International Sociological Associations, Brisbane, Australia, 1-18.

(30) Van der Heijden, K. (1996). Scenarios: the art of strategic conversation. Wiley, New York.

(31) Wolford, W. (2003). Producing community: the MST and land reform settlements in Brazil. Journal of Agrarian Change, 3, 500-520.

(32) Wong, H.Y. \& Rosenhead, J. (2000). A rigorous definition of Robustness Analysis. Journal of the Operational Research Society, 51, 176-182. 